\title{
EDUCAÇÃO SOCIAL E POLÍTICAS PÚBLICAS DE JUVENTUDE: EXPERIÊNCIAS SOCIOEDUCATIVAS NO BRASIL E EM PORTUGAL
}

\author{
EDUCACIÓN SOCIAL Y POLÍTICA PÚBLICA DE JUVENTUD: \\ EXPERIENCIAS SOCIO EN BRASIL Y PORTUGAL
}

\author{
SOCIAL EDUCATION AND YOUTH PUBLIC POLICY: SOCIO- \\ EDUCATIONAL EXPERIENCES IN BRAZIL AND PORTUGAL
}

\author{
Cândida Andrade de MORAES ${ }^{1}$ \\ Augusto Cesar Rios LEIRO ${ }^{2}$
}

\begin{abstract}
RESUMO: A partir do binômio educação e juventude, o presente artigo discute as experiências socioeducacionais de jovens participantes de projetos sociais vinculados a políticas de juventude dos governos centrais do Brasil e de Portugal. O estudo é parte da pesquisa desenvolvida no Programa de Pós-Graduação em Educação da Universidade Federal da Bahia, com estágio na Universidade de Lisboa. Trata-se de uma investigação que objetiva analisar as percepções de jovens sobre a educação social. Com base na sociologia da juventude, a escrita afirma-se como um estudo de caso, de natureza qualitativa, realizado consoante o procedimento metodológico intitulado retratos sociológicos. Toma os depoimentos de dois jovens, um soteropolitano e um lisboeta, como argumento discursivo. As análises de conteúdo realizadas demonstram que os jovens sentem acolhimento e estabelecem fortes laços de amizade nos projetos sociais, ao passo que criticam práticas tradicionais de ensino. Compreendem a comunidade e o bairro social, como espaços de pertencimento e de construção da cultura juvenil, e sonham com um devir em que a formação universitária ocupa lugar de relevo.
\end{abstract}

PALAVRAS-CHAVE: Juventude. Educação Social. Política Pública de Juventude.

RESUMEN: A partir del binomio educación y juventud el presente artículo discute las experiencias socioeducativas de jóvenes participantes de proyectos sociales vinculados a las políticas de juventud de los gobiernos centrales de Brasil y de Portugal. El estudio es parte de la investigación desarrollada en el Programa de Posgrado en Educación en la Universidad Federal de Bahia con período de pasantía en la Universidad de Lisboa. Se trata de una investigación que objetiva analizar las percepciones de jóvenes sobre la educación social. Con base en la Sociología de la Juventud, este texto se afirma como un estudio de caso de naturaleza cualitativa, realizada de modo consonante con el procedimiento metodológico titulado retratos sociológicos. Recoge los testimonios de dos jóvenes, uno soteropolitano (natural de Salvador, Brasil) y un lisboeta, como argumento discursivo. Los análisis de contenido realizados demuestran que los jóvenes

\footnotetext{
1 Doutoranda em Educação pela UFBA; Mestre em Educação e Contemporaneidade pela UNEB; Coordenadora Pedagógica da Secretaria de Educação de Salvador-Bahia. Bolsista PDSECAPES/Ministério da Educação do Brasil/MEC, de setembro/2015 a janeiro 2016. E-mail: candida29moraes@gmail.com.

${ }^{2}$ Doutor em Educação; Professor da UFBA e da UNEB; Coordenador do Programa de Pós-Graduação em Educação da UNEB. E-mail: cesarleirocbce@gmail.com.
} 
sienten acogimiento y establecen fuertes lazos de amistad en los proyectos sociales, al paso que critican prácticas tradicionales de las escuelas. Comprenden a la comunidad y el barrio social como espacios de pertenencia y construcción de cultura juvenil y sueñan con un devenir en que la formación universitaria ocupa un lugar de relevancia.

PALABRAS-CLAVE: Juventud, Educación Social, Política Pública de Juventud.

ABSTRACT: From the binomial education and youth, this article approaches the socio-educational experiences had by young adults on social projects linked to social policies from Brazil and Portugal governments. The study is part of a research developed by the Education Postgraduate Program at Federal University of Bahia (Universidade Federal da Bahia), with an internship held at University of Lisbon (Universidade de Lisboa). This article aims to analyze the youth's perception of social education. Based on Youth Sociology, the paper states a qualitative business case, accomplished according to methodological procedure denominated sociological patterns. It's discursive text based on two young Portuguese speakers' statements, one being from Salvador, Brazil, and one from Lisbon, Portugal. The content analysis shows both young Portuguese speakers engaging to each other and establishing strong friendship relations in social projects, while critiquing conventional education. They comprehend community and neighborhood as places of belonging and youth cultural creation, and have the optimistic hope where a university degree has a place of honor.

KEYWORDS: Youth, Social Education, Youth Public Policy.

\section{Primeiras Palavras ou Saber "colé de mesmo"3}

$\mathrm{O}$ texto discute as experiências de jovens em projetos sociais vinculados a políticas públicas desenvolvidas no Brasil e em Portugal. Para tanto, toma como referência a pesquisa ${ }^{4}$ no âmbito da Educação.

A escrita em questão apresenta uma breve descrição dos estudos desenvolvidos no Brasil e em Portugal, que se ocupam do binômio educação e juventude; em seguida, conceitua política pública e política pública de juventude como categorias teóricas substantivas. A partir do procedimento metodológico intitulado retratos sociológicos reflete sobre a narrativa de dois sujeitos de diálogo a respeito de suas respectivas trajetórias nos projetos sociais e, por fim, apresenta considerações conclusivas acerca do tema.

${ }^{3}$ Expressão utilizada por jovens da Região Nordeste do Brasil, principalmente na Bahia, para questionar um determinado assunto ou situação.

${ }^{4}$ Trata-se de uma pesquisa em andamento no Programa de Pós-Graduação em Educação da Universidade Federal da Bahia. 


\title{
Educação e Juventude ou "Se ligue que é nóis na fita"5
}

A escrita sobre educação e juventude encontra vasta literatura no Brasil e em Portugal. Para efeito do presente artigo, destacamos inicialmente Carrano e Spósito (2003); Novaes (2011) e Abade (2003), no debate sobre Política Pública de Juventude, e, finalmente, mas não menos importante, Groppo (2000), que busca estudar as formas com que se apresentam, atualmente, no Brasil, as práticas socioeducativas direcionadas aos jovens, compreendendo os sentidos atribuídos à juventude no Brasil.

Já nos debates teóricos portugueses, importa destacar Pais (1993), Ferreira (2008) e Vieira (2015). Estudos apontam, em sua diversidade, a heterogeneidade e a sinuosidade como caracterizações dignas de nota. Na esteira desta discussão, a juventude é apresentada como categoria e há tendência de se pensar o jovem para além do recorte etário, como sujeito social e protagonista da constituição da cultura juvenil.

Tratar da juventude envolve diversos aspectos a serem analisados, e, prioritariamente, é interessante sinalizar que não existe apenas uma juventude ou apenas uma cultura juvenil, mas uma multiplicidade delas, diferenciadas a partir das condições históricas e sociais. Pais (2003) amplia a ideia única de jovem, utilizando o termo juventudes, pois:

\begin{abstract}
A juventude começa a ser uma categoria socialmente manipulada e manipulável e, como refere Bourdieu, o fato de se falar dos jovens como uma 'unidade social', um grupo dotado de 'interesses comuns' e de se referirem estes interesses a uma faixa etária de idades, constitui, já de si, uma evidente manipulação. Na verdade, nas representações correntes da juventude, os jovens são tomados como fazendo parte de uma cultura juvenil 'unitária'. No entanto a questão que se coloca a sociologia da juventude é a de explorar não apenas as 'similaridades' entre os jovens, mas também, e principalmente, as 'diferenças sociais' que entre eles existem. (PAIS, 2003, p. 28)
\end{abstract}

Tomando a sociologia da juventude como referencial para pensar o lugar do jovem na Educação, é importante considerar que as práticas voltadas para os jovens, assim como os currículos do sistema regrado de ensino, pouco dialogam com as culturas juvenis tão bem explicitadas por Pais (2003) e diferentes autores no Brasil, como Dayrell (1996) e Abramo (1994), entre outros.

\footnotetext{
${ }^{5}$ Expressão utilizada na Bahia por jovens, com intuito de chamar a atenção do ouvinte/interlocutor para algo ou alguma coisa importante.
} 
Para além da educação formal, a vivência educativa da juventude vem acontecendo nos espaços de educação social promovidos pelas comunidades, em parceria com diferentes instituições e políticas públicas. Esta pesquisa toma a Educação Social como lócus de interlocução e a compreende na perspectiva de ação da Pedagogia Social.

Pensamos a Pedagogia Social como uma ação teórico-prática, socioeducativa, realizada por educadores ou agentes sociais. Ela pode ser vista como um campo de estudo onde a conexão entre Educação e a Sociedade é prioritária, ou ainda, uma esfera de atividades em diferentes espaços não formais de educação que combatem e amenizam os problemas sociais por meios de ações socioeducativas. Moraes (2011).

\section{Política Pública de Juventude No Brasil e Portugal: na "pegada" ${ }^{6}$ dos jovens}

Diferentes são os conceitos sobre políticas públicas. Dentre as distintas abordagens, destacamos a compreensão de política pública como "um conjunto de ações do governo que irão produzir um efeito específico" (LYNN, 1980), ou ainda: "política pública é a soma das atividades dos governos, que agem diretamente ou através de delegação, e que influencia na vida de cidadãos" (PETERS, 1992.

Para as Políticas Públicas de Juventude que consideram um recorte etário, ter uma ação intencional de longo prazo é fundamental, pois isso significa a possibilidade de atingir um quantitativo maior de jovens e uma diversidade de culturas e grupos juvenis próprios de um país plural, como é o caso do Brasil: jovens indígenas, jovens do movimento negro, jovens de movimentos estudantis, jovens feministas, jovens do campo, jovens ligados ao movimento LGBT, jovens mães, jovens trabalhadores urbanos, jovens ligados aos grupos culturais e religiosos, dentre outros.

Para dar conta desta população juvenil, crescente e diversa, a Secretaria Nacional de Juventude ${ }^{7}$ (SNJ), criada em 2005 e vinculada à Secretaria da Presidência da República do Brasil, tem a tarefa de formular, coordenar e integrar as políticas públicas de juventude, interligando-se ao Conselho Nacional de Juventude (CONJUVE), aos

\footnotetext{
${ }^{6}$ Expressão utilizada por jovens na Bahia que pode conotar “encontro”, “aproximação”, “vínculo”. O termo aqui utilizado suscita a nossa itinerância/trajetória na pesquisa de campo para chegar ao encontro dos jovens sujeitos da pesquisa.

7 Disponível em: <http://www.juventude.gov.br/sobre-a-secretaria/view>. Acesso em: 23 de maio de 2016.
} 
Conselhos Estaduais e aos Conselhos Municipais. Em relação à comunicação internacional, a SNJ integra a Organização Ibero-Americana de Juventude ${ }^{8}$ (OIJ) desde 2010, representando a juventude brasileira.

O artigo Juventude e Políticas Públicas no Brasil busca traçar um perfil das políticas públicas, anteriores a 2003, e, para tanto, discute a compreensão de políticas públicas sobre juventude:

É uma ideia relevante para a compreensão das políticas públicas recentes destinadas aos jovens no Brasil - que há uma interconexão entre aquilo que tende a se tornar uma representação normativa corrente da idade e dos jovens na sociedade e o próprio impacto das ações políticas. Dito de outra forma, a conformação das ações e programas públicos não sofrem apenas os efeitos de concepções, mas pode, ao contrário, provocar modulações nas imagens dominantes que a sociedade constrói sobre seus sujeitos jovens. (CARRANO; SPÓSITO, 2003, p. 18, grifos dos autores)

Chamamos a atenção, a partir do recorte acima, para a sutileza das estratégias que podem ocultar as políticas públicas direcionadas à juventude no Brasil, e a necessidade de cuidar para que estas não sejam "um retrato passivo de formas dominantes de se conceber a condição juvenil”. Esta condição juvenil, segundo Abad (2003), pode ser percebida como:

Hoje, dificilmente se pode negar que os jovens, inclusive os do meio rural, têm-se convertido numa categoria social, interclassista e comum a ambos os sexos, definida por uma condição específica que demarca interesses e necessidades próprias. (ABAD, 2003, p. 23)

A condição juvenil é caracterizada por uma forte autonomia individual, pela avidez em multiplicar experiências vitais, por uma rápida maturidade mental e física e por uma emancipação mais precoce, nos aspectos emocionais e afetivos. Tais fatores, aliados à emergência plural e massificada dos novos atores sociais, entre eles os jovens, não encontrando acomodação nos velhos formatos institucionais, têm pressionado por políticas sociais, reformas legislativas e novos contratos sociais, para que a especificidade e as dimensões da nova condição juvenil sejam reconhecidas. Nesse sentido, as políticas sociais citadas por Abade (2003) referem-se especialmente à criação de políticas públicas com recorte para a juventude.

${ }^{8}$ Disponível em: <http://www.juventude.gov.br/politica〉. Acesso em: 23 de maio de 2016. 
Buscando compreender as políticas setoriais, dentro da proposta de ações para a juventude, Novaes (2011, p. 343) classifica as políticas públicas de juventude como: universais, básicas ou estruturais, aquelas que dizem respeito às demandas de distribuição e à universalização de acesso; atrativas, preferenciais ou por afinidades, dirigidas a públicos definidos por critério de renda, ocupação, atividades, local de moradia e outros pertencimentos; específicas ou exclusivamente para jovens, aquelas que se destinam a grupos etários entre 15 e 29 anos, sendo desenhadas de acordo com as características e as demandas do segmento juvenil.

Dentre as políticas pensadas para a juventude brasileira, a partir das solicitações dos movimentos sociais, ${ }^{9}$ e em decorrência das desigualdades e suas consequências no contexto contemporâneo, destacam-se as políticas de saúde, trabalho, educação e, especialmente a política de combate ao racismo e à mortalidade da população jovem negra.

A Secretaria Nacional de Juventude (SNJ), em articulação com organizações sociais de jovens, acolhe debates em torno da mortalidade da juventude, especialmente em relação aos jovens negros. Segundo o Estatuto da Juventude do Brasil (2013), ${ }^{10}$ milhares de vidas são ceifadas durante a juventude, na faixa etária compreendida entre 15 e 29 anos. Dados do Ministério da Saúde (2012) mostram que mais da metade $(53,3 \%)$ dos 49.932 mortos por homicídios em 2010 no Brasil eram jovens, dos quais 76,6\% negros (pretos e pardos) e 91,3\% do sexo masculino.

No que tange às políticas públicas atuais, vigentes no Brasil e voltadas para a população jovem, a SNJ, tomando como referências os dados sobre a taxa de mortalidade da juventude, principalmente nos aglomerados urbanos, implementou um plano estratégico de enfrentamento da violência e com a expectativa de que, de forma interinstitucional, seja possível mobilizar diferentes setores da sociedade pela causa da juventude e na garantia de seus direitos: "Plano Juventude Viva".

A SNJ, ao justificar o porquê de um plano específico para os jovens negros, apresenta os números: os dados do Ministério da Saúde revelam que mais da metade dos homicídios no Brasil (53\%) atinge pessoas jovens, sendo que, deste grupo, mais de $75 \%$ são jovens negros, de baixa escolaridade, em sua grande maioria homens (91\%) e com

9 Conforme relatórios da I Conferência Nacional de Juventude. Disponível em: $<$ http://issuu.com/participatorio/docs/cartilha_i_confer_ncia_nacional_de/1?e=12152407/10688200>. Acesso em: 20 de maio de 2016.

10 Lei 12.852/2013. Disponível em: <http://www.planalto.gov.br/ccivil_03/_Ato20112014/2013/Lei/L12852.htm>. Acesso em: 20 de maio de 2016. 
maior incidência na faixa etária entre 20 e 25 anos. O quadro da última década mostra que é cada vez maior a diferença entre o número de homicídios entre jovens brancos e negros. Em relação ao primeiro grupo, o número de homicídios caiu de 9.248, em 2000, para 7.065, em 2010. Entretanto, em relação aos negros, os homicídios aumentaram de 14.055, em 2000, para 19.255, em 2010. ${ }^{11}$

O Núcleo de Formação de Agentes de Cultura da Juventude Negra (NUFAC) foi uma das ações realizadas através de editais entre o Juventude Viva e a Fundação Palmares para a implementação de atividades formativas de jovens em comunidades das grandes cidades do Brasil. Para desenvolvimento da pesquisa em discussão, utilizamos o NUFAC como referência de trabalho socioeducativo, para a análise qualitativa das experiências em espaço não escolar de educação da juventude.

Em Salvador, na Bahia, o NUFAC aconteceu através da ONG Cipó Comunicação Interativa, ${ }^{12}$ que implementou o projeto, com a participação de educadores sociais e de coordenadores já vinculados à comunidade, o que favoreceu o estabelecimento de laços e o desenvolvimento do trabalho. ${ }^{13}$

No contexto de Portugal, a organização da gestão de políticas para a juventude acontece atualmente através do Ministério da Presidência e dos Assuntos Parlamentares, via Secretaria do Estado do Desporto e Juventude e do Instituto Português de Desporto e Juventude.

Segundo o e-gov português, promove-se uma política integrada e descentralizada para as áreas do desporto e da juventude, em estreita colaboração com entes públicos e privados, designadamente com organismos desportivos, associações juvenis, estudantis e autarquias locais. Esta política visa dinamizar o apoio ao associativismo, ao voluntariado e à promoção da cidadania, à ocupação de tempos livres, à educação não formal, à informação e à mobilidade geográfica dos jovens, em Portugal e no estrangeiro.

Muitos são os programas e projetos desenvolvidos pela gestão de políticas públicas de juventude do governo português, entre eles, encontramos o Programa Garantia Jovem, o Programa Jovens Criadores, o Projeto CUIDA-TE, o Programa

11 Perguntas e Respostas Juventude Viva, site da Secretaria Nacional da Juventude. Disponível em: <http://juventude.gov.br/juventudeviva/faq>. Acesso em: 15 de maio de 2016.

${ }^{12}$ Disponível em: <http://cipo.org.br/>. Acesso em: 17 de maio de 2016.

$13 \mathrm{Na}$ tese em discussão, são apresentados extratos de entrevistas com gestores da política pública Juventude Viva, coordenadores pedagógicos da ONG Cipó e educadores sociais que atuaram como formadores de juventude no NUFAC. Para este artigo, são trabalhadas duas entrevistas com os jovens, considerando o objetivo do texto. 
Arrendamento 65 e o Programa OTL - Ocupação dos Tempos Livres e Juventude em Ação/Erasmus.

O Observatório Permanente da Juventude (OPJ), vinculado ao Instituto de Ciências Sociais (ICS) da Universidade de Lisboa (UL), realizou a pesquisa Legislação da Juventude em Portugal. A informação é apresentada pela ordem cronológica dos governos constitucionais, e por áreas temáticas, de acordo com o conteúdo do resumo de cada ato legislativo.

A base de dados que elenca todas as resoluções e emendas relativas aos jovens de Portugal, disponibiliza link específico para legislação na íntegra. Além das políticas, programas e projetos citados, identificamos, através do Alto Comissariado das Migrações, o "Programa Escolhas", ${ }^{14}$ que atua, desde 2001, na gestão e no financiamento de organizações não governamentais, e apoia intervenção social e educativa junto à população portuguesa que vive em condições de relativa vulnerabilidade, em comunidades denominadas "bairros sociais". O programa, que nasceu em 2001 tem como objetivo promover a inclusão social de crianças e jovens de contextos socioeconômicos vulneráveis, visando a igualdade de oportunidades e o reforço da coesão social.

Após busca ativa e análise de material do Programa Escolhas, além de entrevistas com gestores da referida política, selecionamos o Projeto Percursos Acompanhados, realizado na comunidade do Zambujal - Amadora, Lisboa, para realizar observações, entrevistas e vivências com a comunidade.

O projeto Percursos Acompanhados foi criado pelo Centro de Estudos para Intervenção Social (CESIS), ${ }^{15}$ que tem como objetivo formular e implementar políticas de desenvolvimento humano e social, intervindo com ações formativas e educativas em comunidades. O projeto Percursos Acompanhados aconteceu durante dez anos, tendo sua última turma no ano de 2015, com financiamento do Programa Escolhas, visando "acompanhar" e orientar os jovens na continuidade dos seus percursos escolares, e promovendo diferentes situações didáticas e pedagógicas para que os jovens pudessem alcançar o ensino regular obrigatório, que é o Ensino Secundário (equivalente ao Ensino Médio no Brasil), e facilitar sua entrada no mercado de trabalho.

Através da política pública do Alto Comissariado das Migrações, via o Programa Escolhas, alcançamos o CESIS e consequentemente investimos o nosso olhar

${ }^{14}$ Disponível em: <http://www.programaescolhas.pt/>. Acesso em: 20 de maio de 2016.

${ }^{15}$ Disponível em: <http://www.cesis.org/pt>. Acesso em: 20 de maio de 2016. 
investigativo nas atividades socioeducativas desenvolvidas nesta organização com jovens provenientes de famílias cabo-verdianas, pertencentes ao bairro social Zambujal, onde o CESIS atua.

Após a apresentação do contexto das políticas públicas de juventude no Brasil e em Portugal, com a definição dos dois casos de pesquisa, é possível registrar o diagrama a seguir, que corresponde ao nosso percurso de campo em busca/encontro dos jovens interlocutores, nos dois países em tela:

Figura 1: Políticas Públicas de Juventude e Projetos Sociais.

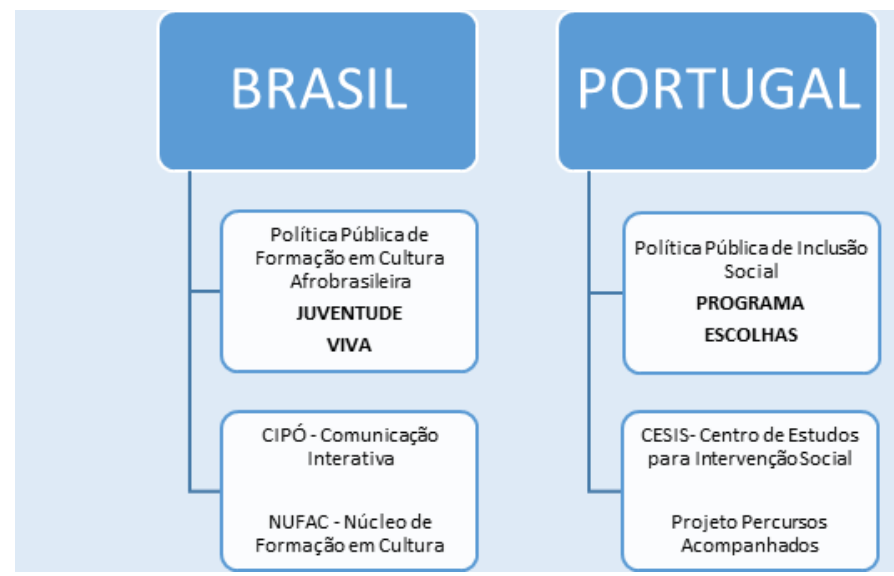

Fonte: elaboração dos autores.

No encontro com os programas e projetos das Políticas Públicas de Juventude, a realização da pesquisa de campo permitiu a "pegada" ou interação dos pesquisadores com os sujeitos da pesquisa.

Assim, importa uma breve apresentação dos dois jovens entrevistados, eleitos aqui como sujeitos de diálogo, ${ }^{16}$ de modo que o leitor possa estabelecer nexos entre o que o sujeito diz e aquilo que está sendo dito acerca das experiências da juventude.

\section{Os Sujeitos de Diálogo: Vozes Juvenis}

As vozes, eleitas para análise, refletem as experiências socioeducativas e as vivências na comunidade ou bairro social dos jovens participantes dos projetos sociais. A escolha dos dois sujeitos de diálogo decorreu do limite textual, de critérios da

${ }^{16}$ Elegemos apresentar dois jovens, um do Brasil e outro de Portugal, a título de organização e limite que um artigo oferece, de modo que possamos fazer a fala e a vida dos jovens se tornarem tão presentes e inteiras no texto quanto as análises teórico-metodológicas realizadas, entendendo o jovem como sujeito e ator social da sua história. 
equidade de gênero e expressão singular dos jovens, na ambiência da sua comunidade ou bairro social.

A metodologia de análise adotada é inspirada nos retratos sociológicos de Lahire (2004) pela qual o sociólogo descreve que a sociologia apresenta as forças às quais somos confrontados a partir do nascimento e que determinam a forma como sentimos, pensamos e agimos e nos auxilia a progredir no conhecimento de nós mesmos e dos outros. A utilização da metodologia dos retratos sociológicos nos conduz a um novo olhar, na medida em que inscreve a experiência científica e educacional de um ator individual no conjunto de sua trajetória social (LIMA JUNIOR; MASSI, 2015).

Importa destacar que as entrevistas realizadas seguiram um roteiro comum aos dois jovens e o recorte analítico valorizou o dizer referente à experiência no projeto social.

\section{Juca: O Multiartista da Comunidade}

Juca define-se como dançarino, ator, produtor e cineasta. Tem 22 anos, filho único e mora com a mãe. Concluiu o Ensino Médio em uma escola pública do bairro e vem prestando o Exame Nacional do Ensino Médio (ENEM), na expectativa de obter uma pontuação favorável para ingressar no Bacharelado Interdisciplinar em Artes da Universidade Federal da Bahia. É dançarino e produtor do Herdeiros de Angola, grupo artístico formado por jovens do bairro da Plataforma.

Analisa a sua experiência escolar, toda a trajetória vivida em escolas públicas em Salvador, como um espaço que "não contava a verdadeira História". Segundo ele, a escola ensina uma História que veio de fora e não representa o que o jovem é, não mobiliza o seu entendimento sobre a própria identidade. "Foi o curso do NUFAC que me deu a oportunidade de ter a questão, mesmo, das Histórias Negras, das lutas negras que fizeram o Brasil. Foi através dessas lutas que o Brasil é o que é hoje. Um país de miscigenados. A questão da abordagem dos temas que estão na nossa realidade. Que tem alguns temas que eles tocam na escola, que não é da nossa realidade".

A relação entre o que é ensinado na escola e o que é vivido nas comunidades, é tomada por Juca como um conteúdo sem sentido para quem está vivenciando a aprendizagem. Por isso, ele entende que a oferta, no curso de finalização de vídeo, de um módulo intitulado Relações Étnicas Raciais foi importante: "Para deixar claro que o 
jovem negro pode, sim. Que ele pode estudar, ele pode ir para uma universidade. Que ele pode ser um profissional capacitado na sua área e que ele pode, sim, ser um profissional bem-sucedido, e virar referência”.

Quando questionado sobre o que, de fato, pôde aprender no projeto social NUFAC, ele esclarece que houve dois tipos de saberes: o prático e o da vida. Aprender sobre a experiência da população africana no Brasil e ter a compreensão de que é um afrodescendente ganhou um lugar de destaque na fala dele, que faz uso desse saber como um sentimento de pertença: "O que mais marcou foi a questão de me informar do que eu posso. Me informar sobre questões que são minhas. Que vêm dos meus antepassados e que eu posso ir para a frente com isso".

Segundo Juca, muitos jovens entram nos cursos dos projetos sociais para ter ajuda financeira, mas, no decorrer do tempo, quando conseguem alguma atividade remunerada, desistem do projeto. Ele explica que dificuldades com transporte, como não ter dinheiro para pegar o ônibus e ainda "os problemas familiares que acontecem na casa de todos os jovens", dificultam a sua permanência nos projetos.

O interesse em ampliar os conhecimentos em vídeo e formação cultural, na comunidade, fizeram com que Juca permanecesse no curso: "também a minha mãe trabalha e me ajuda, por isso não passo tanta dificuldade”. Para ele, os colegas do curso desistem quando enfrentam dificuldades financeiras. "Eu pude me fortalecer enquanto pessoa e futuramente ser um bom profissional, por que o curso me fortaleceu também como profissional [...]; e não deixei as coisas me abaterem, como o atraso para pagar os transportes".

A relação com a comunidade já era vivida por Juca, ao participar das atividades do Herdeiros de Angola. Estar no projeto NUFAC mudou sua forma de ver a comunidade, assim como a forma de ver a Bahia e o Brasil. Evidencia, após o projeto social, as diferentes oportunidades que a comunidade pode oferecer a um jovem. "Moro na verdade em outro pedaço do bairro, um lugar mais distante [...]; então, a gente sabe que tem gente que pode te ajudar e tem gente que pode te levar para baixo".

Apesar de destacar, em muitos momentos, a diferença entre o projeto social e a escola, ele critica a comunicação dos projetos para chamar os jovens a conhecer e participar. Segundo ele, muitos projetos existem com número baixo de participação, pois "a forma de convidá-los não é atrativa". Apesar de usar conteúdos que chegam "perto do jovens", o convite não usa a linguagem dos jovens. "Eu acho que tem vários cursos, tem várias oportunidades mesmo de tentar tirar o jovem, tanto da marginalidade 
quanto do comodismo. Mas essa informação quando chega, chega de forma deturpada, e não chega de forma tão instigante. Por que tem jovens que sabem dessas oportunidades, mas não vão porque essa informação não chegou até ele. Não foi, talvez, na linguagem dele. Não foi pelo meio de comunicação que ele mais usa".

A relação da educadora social e a forma lúdica de ensinar sobre a vida e o processo de finalização de vídeo (técnica) são relatados com destaque. Para Juca, a possibilidade de falar sobre o que está aprendendo e de promover debates foi um ganho para todos da turma em que participou. Como se considera comunicativo, a relação com a educadora e com as atividades que ela propunha foi favorável ao desenvolvimento da técnica, mas também para compreender como usar a técnica na prática social.

Com o fim do NUFAC, que durou um ano, Juca deu continuidade a outras atividades formativas, na própria CIPÓ e no CCP, além das atividades permanentes no grupo Herdeiros de Angola. O espaço socioeducativo aparece aqui como uma ocupação criativa do tempo de Juca, que já não está mais na educação formal, nem mesmo atua em atividades profissionais formais.

Há um sentimento de pertença à organização não governamental, assim como ao centro cultural, que Juca utiliza para ensaiar, no palco, peças do grupo ou as coreografias, que ele mesmo monta. Aliado aos cursos que deu continuidade, atualmente produz roteiros e vídeos, contando sobre a comunidade de Plataforma e a questão do jovem negro em Salvador.

“Eu, na verdade, não parei por esse mesmo processo de ter esse domínio da formação audiovisual. Eu continuei escrevendo roteiros. Vou continuar filmando o segundo episódio da websérie 'Mandinga', utilizando pessoas do próprio bairro. Continuar a utilizar os equipamentos da CIPÓ, como um jovem em formação mesmo. Como eu falei, eu me inscrevi no ENEM. Pretendo cursar. Pretendo seguir, sim”.

Por fim, faz destaque ao desejo de ser formador e de ensinar e atuar em projetos sociais. "Na verdade, eu me vejo mesmo disseminador do que eu aprendi. Seja em projeto, seja como forma mais profissional. Produzindo vídeos e ser visto por um lado mais profissional. Por estar por trás de um filme, ou estar num projeto, colocando tudo que eu aprendi”. 


\section{Mafalda: O Devir do Afeto}

"Sou uma pessoa extrovertida, inteligente e esforçada. Moro com minha família e tenho uma boa relação com meus pais e meu irmão. Minha avó paterna veio de São Tomé para morar aqui. Minha avó materna é do Porto, Norte de Portugal, mas veio morar aqui em Lisboa. E meu avô paterno era cabo-verdiano e também veio para Portugal".

As origens de Mafalda apontam para a diversidade étnica e cultural que tem enriquecido a sociedade portuguesa, nas últimas décadas. Ela é uma jovem de dezesseis anos que vive num bairro social, na região da Amadora, cidade vizinha de Lisboa. Apesar de ter estudado todo o período preparatório no Agrupamento Escolar de Alfragide, próximo ao bairro social em que mora, hoje cursa o $10^{\circ}$ ano do Ensino Secundário em Humanidades, na Escola do Restelo, bairro nobre da cidade de Lisboa, e se prepara para ingressar na universidade.

"Hoje eu estudo numa escola num meio completamente diferente, estou no Restelo, ao pé de Belém, então, quando digo que venho do bairro social, eles dizem... ‘Ah, tu é de um bairro?' Então, não vejo assim, além de toda gente sabe sobre bairro social, eu me sinto completamente segura. Gosto do meu bairro, e sei que tem coisas que vêm desenvolvendo e crescendo com associações".

Mafalda diferencia as experiências escolares, vividas na escola próxima ao bairro social da escola nova, localizada numa região nobre de Lisboa. Para ela, os jovens que frequentam a Escola Secundária, no curso de Humanidades, não a vêm como "rapariga do bairro social" e desconfiam de que ela viva realmente em um desses bairros.

Segundo ela, os colegas têm um preconceito em relação ao bairro, acham que “toda gente é má". E não acreditam nela. "Olha, não parece que vem do bairro, não se comporta como as pessoas que vêm do bairro! Eu estou num ensino regular e eles acham que eu devia estar no ensino profissional. Eles dizem que não me visto nem me comporto como uma pessoa de bairro. Como se as pessoas do bairro social, todas se vestissem mal, se comportassem mal. Eu acho que não tem nada a ver. Explico que as pessoas que moram no bairro não têm condições de comprar casas, mas isso não implica nada. Não implica a forma de falar, a forma de se vestir...". 
A trajetória escolar de Mafalda aconteceu próxima ao bairro social, onde vivem hoje as suas avós, materna e paterna. Ela nasceu no bairro social, mas os pais se mudaram para Queluz, quando ela tinha seis anos: "Quando eu era pequenina, eu morava aqui, mas eu ficava mais em casa. Mas mesmo morando em Queluz, eu vinha para o CESIS e andava aqui na rua com meus amigos. Meus avós moram aqui e eu moro com meus pais em Queluz, fui para lá tem uns dez anos. Mas meus amigos, todos são daqui. A minha vida foi toda aqui, ainda é, só vou para casa dormir. Meus pais não queriam criar os filhos no bairro social, não queriam que fossem para a rua. Bom, é isso que meu pai me diz". Para ela, o fato dos pais terem mudado de bairro, quando ela tinha seis anos, por não desejarem "criar os filhos no bairro social" não impediu que ela construísse todos os seus vínculos naquele espaço.

No Ensino Primário e Preparatório, estudou na Escola Azul de Alfragide, onde diz estar mais habituada, porque eram as pessoas do bairro social, onde ela se sentia segura. "Me sentia mais à vontade, mas eu chumbei ${ }^{17}$ no oitavo ano, não estava focada. Mas foi mesmo uma estupidez, foi um ano perdido, porque foi burrice da minha parte. Foi mesmo porque eu não estava focada, depois foquei, porque foi como um choque. Ok, chumbei! Então acordei. Um click!”.

Na saída do Ensino Preparatório, como tinha boas notas, uma pontuação que ela podia escolher para onde iria, diz que deixou claro para as pessoas da escola que conversaram com ela que ela ia fazer universidade e que queria cursar Direito. "Meu pai começou a cursar Direito, mas não concluiu, ele trabalha como vigilante e isso não é fácil...". Para entrar no Ensino Secundário, "Eu escolhi essa escola no Secundário, porque é uma das melhores escolas de Portugal, e eu queria me preparar para ir para a universidade. Na minha Escola Almeida Garret, fizeram testes comigo e me deram resultados, me perguntaram o que eu queria ser, e eu disse que queria fazer Direito e só conseguiria indo para Humanidades".

Atualmente, cursando o décimo ano, ela se diz em adaptação, pois "é completamente diferente. Foi um bocadinho difícil, não dei tudo que devia ter dado, devia ter me aplicado mais, mas pronto! Não me esforcei tanto e a escola, como é exigente, foi muito difícil acompanhar".

Para Mafalda, há uma diferença entre ela e os colegas, pois alguns dos colegas de sala já estavam estudando nesta escola, considerada uma das melhores do país, desde

${ }^{17}$ Expressão utilizada em Portugal para designar a reprovação em um ano letivo. Geralmente atribuído aos anos de escolarização obrigatória, até o Ensino Secundário, que equivale ao Ensino Médio no Brasil. 
o sétimo ano. Desse modo, avalia que eles estão acostumados com o ritmo intenso das aulas, a quantidade de atividades e a disciplina de estudos, que é muito exigente. “Aquela escola é do sétimo ao décimo, mas eu vim de fora, diferente dos alunos de lá. Estes alunos de lá estão habituados àquele ritmo e as pessoas que vêm de fora caem de paraquedas. A forma de ensinar é diferente. Aquela escola como, está habituada a estar no topo, aperta muito, os professores exigem muito, tem os objetivos". Mafalda mostrase cansada e diz que as aulas são longas, com muitas horas de fala das professoras, mas não pretende desistir, pois vai para a universidade.

Sobre o Projeto Percursos Acompanhados, a jovem narra com ênfase suas etapas de experiência, ao longo de quase sete anos. Mostra-se emocionada em descrever as atividades e demonstra um vínculo afetivo, construído ao longo deste tempo, com os educadores sociais, a psicóloga e a assistente social. "Entrei no CESIS do quarto para o quinto ano, é muito tempo que fiquei, acho que sete anos. É difícil contar o que vivi aqui, é mesmo difícil. Não sei como dizer. Foram muitas coisas que vivi aqui, não sei como dizer. Aprendi muita coisa, de tudo".

As atividades de acompanhamento dos estudos, realizados geralmente por uma educadora social ou um educador, que promove também momentos de socialização, o Percursos Acompanhados realizava momentos de conversas individuais, dos jovens com uma psicóloga, que foi uma forma importante que Mafalda teve, de apoio constante. "O CESIS me ensinou a forma como estar, de eu acreditar em mim, os meus objetivos, a lutar pelos meus direitos, a cumprir com meus deveres. O CESIS me ajudou imenso".

Mafalda diz do seu conceito de ser jovem. Entende que é uma fase complicada, pois a maioria deles, e se inclui na fala, acha que tem sempre razão e passa a ter uma certa rebeldia, quando não são beneficiados de algum modo. Explica ainda que sente falta de não ter mais as atividades de socialização e de escuta com a psicóloga: "Eu fui uma jovem rebelde, que eu faltava imenso, dizia que vinha e depois não vinha e, agora que não tem, sinto imensa falta, sinto imenso. É que as vezes temos uma coisa e não damos valor. Era assim, era sempre alguém em cima de mim a cobrar, agora não tem. Era como uma imensa família, se precisávamos de alguma coisa, vínhamos cá, sempre estávamos cá”.

Ao descrever a importância do projeto para a sua vida, diz que a ação socioeducativa desenvolvida pelo CESIS "mudou a pessoa que eu era, desde que eu entrei até agora. Acho que se não tivesse a oportunidade de estar aqui, acho que seria uma pessoa diferente, em tudo, mas não sei explicar, é complicado...”. 
Para Mafalda, o CESIS faz parte do seu percurso de escolarização, mas também é o espaço no qual ela adquiriu os laços de amizade e confiança. Mostra-se mobilizada pela paralisação das atividades, em decorrência da ausência de financiamento do Programa Escolhas para a sexta geração. "É tudo, são todas as atividades importantes, não há uma atividade, é muita coisa. Eu tenho pena dos jovens que começaram agora a atividade e de repente perderam tudo".

Idealiza ajudar o CESIS a reconstruir o projeto para ajudar os outros jovens do bairro social: "Se fosse para fazer de novo, eu podia fazer, tentava, mas acho que não ia conseguir. Mas acho complicado porque tem que ter alguma experiência para se comunicar com os jovens. Na nossa idade, é bastante complicado. Não sei se eu ia conseguir, mas se me dessem a oportunidade, eu tentava fazer um projeto".

\section{Pronto, tá feito! ${ }^{18}$ Sínteses Possíveis}

Para refletir sobre as narrativas dos jovens, num primeiro momento, foram discutidos o binômio educação e juventude. Em seguida, o contexto mais recente das políticas públicas de juventude no Brasil foi descrito. Em Portugal, a política pública apresentada situa-se no âmbito das políticas de migração, com atenção à inclusão social de jovens. Os dois projetos socioeducativos explicitados, o primeiro, no Brasil, teve como foco a cultura e a formação étnico-racial, e o segundo, em Portugal, deu ênfase ao acompanhamento dos jovens para a continuidade e a progressão escolar.

Convidar o leitor a entrar conosco no terreno luso-brasileiro através da lente dos jovens foi a nossa meta, no segundo momento deste texto. Através de entrevistas compreensivas $^{19}$ com dois jovens, do Brasil e de Portugal, ${ }^{20}$ as vozes dos sujeitos da pesquisa deram vida aos vínculos e às dificuldades vivenciadas no projeto social, no bairro social e na comunidade. Observamos que as análises iniciais suscitam a ideia de que, tanto Juca quanto Mafalda, vivenciam a experiência de serem sujeitos e atores sociais da educação.

${ }^{18}$ Expressão informal ou gíria utilizada por jovens, em Portugal, para designar que algo está finalizado ou assunto daquele momento.

${ }^{19}$ Entendemos, por entrevista compreensiva, uma técnica qualitativa de recolha de dados, que articula formas tradicionais de entrevistas semidiretivas a técnicas de entrevista de natureza mais etnográfica. (FERREIRA, 2014).

${ }^{20}$ Para a realização da pesquisa em Portugal, contamos com o apoio e a coorientação do Professor Doutor Vítor Ferreira, através do Observatório Permanente de Juventude do Instituto de Ciências Sociais da Universidade de Lisboa. 
Como sínteses possíveis, trabalharemos com a ideia de comunidade e bairro social, considerando-os enquanto espaço de atuação da Educação Social. No registro clássico da Educação Social, da Pedagogia Social de Paul Natorp (1913), somos informados que a comunidade é o espaço privilegiado de exercício da ação educativa. Isto de modo a compreender melhor a Educação Social, enquanto prática transformadora e subsidiada pela teoria da Pedagogia Social, como se chama a atenção:

\begin{abstract}
A Pedagogia Social emerge, no Brasil, como uma ciência que oferece as bases metodológicas e teóricas para a Educação Social. A Educação Social, por sua vez, constitui-se em uma dimensão prática onde acontece a aplicação das técnicas, metodologias, dinâmicas geradas no diálogo com a Pedagogia Social. Se uma se associa à teoria, a outra se associa à prática. No entanto as duas devem caminhar juntas assim como a reflexão e a ação: uma constrói e alimenta a outra. Sem prática não tem teoria; sem teoria a prática arrisca a se tornar um ritual sem sentido. (CALIMAN, 2010, p. 351-352)
\end{abstract}

Para Mafalda e Juca, seja em Portugal ou no Brasil, respectivamente, estas práticas de Educação Social motivaram tanto a relação de confiança com os educadores sociais e demais profissionais do espaço de ação socioeducativa, quanto a aprendizagem dos saberes necessários à vivência em demais espaços, como saber ser e conviver com os outros (na família, no bairro, na escola, no palco, em espaços profissionalizantes).

A confiança de Mafalda, no espaço do projeto social, fica evidente, quando ela cita a sua forma de ser vista e percebida: "E alguém dizer que falou com minha professora e que não estava tudo bem e dizer... E me diz, me conta lá, o que que se passa?" Esta possibilidade de interação e integração pela comunicação com a escola, um dos principais objetivos do Projeto Percursos Acompanhados, mobilizou a capacidade de Mafalda, ao se perceber observada e cuidada na ação socioeducativa, para além da aprendizagem dos conteúdos conceituais de cada área estudada.

Já Juca descreve, em suas narrativas, diferentes situações, nas quais o vínculo com a educadora e também com a comunidade se tornam oportunidades de aprendizagens: "A educadora foi uma pessoa super importante na minha vida [...] colocava o assunto em prática de uma forma muito lúdica, eu acho que é isso, a forma mais prática de chegar até a pessoa".

Assim, se para Mafalda o bairro social aparece como um espaço de pertencimento e construção de vínculos, deixa isso claro, quando afirma que, apesar de residir em outro bairro por decisão dos pais, ela estabeleceu as amizades naquele lugar e é ali que passa quase toda a sua rotina, Juca ressignifica a cultura juvenil da comunidade, ao atuar 
como ator, diretor, coreógrafo e produtor. Para estes jovens, a comunidade e o bairro social impregnam suas vidas atingindo um lugar central e educativo, pois se inscrevem como espaços-tempos de enaltecimento da diferença e de exercício de cidadania.

\section{REFERÊNCIAS}

ABAD, M. Crítica política das políticas de juventude. In: FREITAS, M. V.; PAPA, F. C. (Orgs.). Políticas públicas: juventude em pauta. São Paulo: Cortez, 2003.

ABRAMO, H. W. A. Cenas juvenis. São Paulo: Scritta, 1994.

ABRAMO, H. W. A.; BRANCO, P. P. M. (Orgs.). Retratos da juventude brasileira: análises de uma pesquisa nacional. São Paulo: Fundação Perseu Abramo, 2008.

CALIMAN, G. Pedagogia social: seu potencial crítico e transformador. Revista de CIÊNCIAS da EDUCAÇÃO - UNISAL, Americana, SP, ano XII, n. 23, p. 341-368, $2^{\circ}$ sem. 2010.

CARRANO, P.C.R.; SPÓSITO. M. P. Juventude e Políticas Públicas no Brasil. Revista Brasileira de Educação. Set /Out /Nov /Dez, 2003.

DAYRELL, J. Múltiplos olhares sobre educação e cultura. Belo Horizonte: Editora UFMG, 1996.

FERREIRA, V. S. Artes e manhas da entrevista compreensiva. Revista Saúde Sociedade. São Paulo, v. 23, n. 3, p. 979-992, 2014.

FERREIRA, V. S. Marcas que demarcam: tatuagens, body piercing e culturas juvenis. Lisboa: ICS, 2008.

FREITAS, M. V.; PAPA, F. C. (Orgs.). Políticas públicas: juventude em pauta. São Paulo: Cortez, 2003.

GROPPO, L. A. Juventude ensaios sobre sociologia e história das juventudes modernas. Rio de Janeiro: DIFEL, 2000.

LAHIRE, B. Retratos sociológicos: disposições e variações individuais. Porto Alegre: Artmed, 2004.

LIMA JUNIOR, P.; MASSI, L. Retratos sociológicos: uma metodologia de investigação para a pesquisa em educação. Revista Ciênc. Educ., Bauru, v. 21, n. 3, p. 559-574, 2015.

LYNN, L. E. Designing Public Policy: A Casebook on the Role of Policy Analysis. Santa Monica, Calif.: Goodyear. 1980.

MORAES, C. A. Por uma pedagogia social: práticas pedagógicas em escolas para 
jovens em situação de privação de liberdade. 2011. 123 f. Dissertação (Mestrado em Educação e Contemporaneidade) - Faculdade ou Programa, Universidade do Estado da Bahia, Salvador, 2011.

NATORP, P. Pedagogía social: teoria de la educación de la voluntad. Madri: La Lectura, 1913.

NOVAES, R. Entre juventudes, governos e sociedades (e nada será como antes). In: FREITAS, M. V.; PAPA, F. C. (Orgs.). Juventude em pauta: políticas públicas no Brasil. São Paulo: Peirópolis, 2011.

PAIS, J. M. Culturas juvenis. Lisboa: Imprensa Nacional; Casa da Moeda, 2003.

PETERS, B. Guy. Reorganizando o Governo em uma Era de Contenção e Compromisso. Dados, vol. 35, nº 3, p. 301-335, 1992.

SOUZA, Celina. Políticas públicas: uma revisão da literatura. Sociologias, n. 16, p. 2045, dez 2006.

VIEIRA, M. M. (Org.). O futuro em aberto. Lisboa: Editora Mundos Sociais, 2015

\section{Como referenciar este artigo}

MORAES, Cândida Andrade de.; LEIRO, Augusto Cesar Rios. Educação social e políticas públicas de juventude: experiências socioeducativas no Brasil e em Portugal. Revista Ibero-Americana de Estudos em Educação, Araraquara/SP, v. 11, n. esp. 3, p.1626-1644, 2016. Disponível em: 〈http://dx.doi.org/10.21723/riaee.v11.n.esp3.9065>. E-ISSN: 1982-5587.

Submetido em: agosto/2016

Aprovado em: novembro/2016 